\title{
Essential oil composition variability among natural populations of Pinus mugo Turra in Kosovo
}

\author{
Avni Hajdari ${ }^{1,2^{*}}$, Behxhet Mustafa ${ }^{1,2}$, Gresa Ahmeti ${ }^{1}$, Bledar Pulaj ${ }^{1}$, Brigitte Lukas ${ }^{3}$, Alban Ibraliu 4 , \\ Gjoshe Stefkov ${ }^{5}$, Cassandra L. Quave $e^{6,7}$ and Johannes Novak ${ }^{3}$
}

\begin{abstract}
Pinus mugo Turra, is a native pine species in central and southern Europe, growing in high mountains area (altitudes 1.800-2.300 m.a.s.I.). In Kosovo, it is one of the native pines too, distributed in high altitudes in the Sharri Mountains and Albanian Alps Mountains. Its populations represent an important wealth of essential oil resources available, which make this species very important in terms of economic values. The chemical composition and yields of the essential oils of dwarf pine (Pinus mugo Turra) needles, twigs and cones from six wild populations in Kosovo were investigated with the aim to assess their natural variability. The identity of $P$. mugo was confirmed by morphology and DNA barcoding. Sixty-two compounds were identified representing $69-95 \%$ of the total identified compounds. The yield ranged from $0.3-0.8 \% \mathrm{v} / \mathrm{w}$ in needles, $1.0-2.4 \% \mathrm{v} / \mathrm{w}$ in twigs and $0.1-0.5 \% \mathrm{v} / \mathrm{w}$ in cones, depending on the origin of plant material and plant organs. a-Pinene (needles: 16.9-24.5\%; twigs: 4.5-8.8\%; cones: $3.1-5.6 \%$ ), $\beta$-pinene (needles: 1.5-5.4\%; twigs: 2.2-15.4\%; cones: 1.3-14.2 \%), 8-3-carene (needles: 15.4-27.8 \%; twigs: 24.0-51.6 \%; cones: 10.5-31.5\%), limonene + $\beta$-phellandrene (needles: 1.9-5.9\%; twigs: 12.6-24.2\%; cones: 2.1-9.3\%), (E)-caryophyllene (needles: 4.4-8.9 \%; twigs: 4.0-10.8 \%; cones: 10.3-26.9\%) and germacrene D (needles: 4.0-8.3 \%; twigs: 0.2-6.19\%; cones: $0.1-12.4 \%$ ) were the major components of the essential oil. Principal component analysis (PCA) and hierarchical cluster analyses (HCA) suggests that the population of P. mugo clustering is not related to their geographic location, but rather seemed to be linked to local selective forces acting on chemotype diversity. Low variability related to their geographic location has an economic importance since samples originating from different locations in Kosovo can treated with same standards.
\end{abstract}

Keywords: Pinus mugo, Essential oil, Natural variability, Kosovo

\section{Background}

Pinus mugo Turra, Pinaceae (Dwarf pine, Mountain pine) is a pine species that grows in the form of shrubs, up to $3.5 \mathrm{~m}$ high. It grows in high altitudes in the mountains of central and southern Europe at 1.800-2.300 m.a.s.l. (Tutin et al. 1964; Critchfield and Little 1966). Due to its wide ecological amplitude concerning environment factors, it is a pioneer species favourable to colonizing

\footnotetext{
*Correspondence: avni.hajdari@uni-pr.edu

${ }^{2}$ Institute of Biological and Environmental Research, Faculty

of Mathematical and Natural Science, University of Prishtina, Mother

Theresa St, 10000 Prishtinë, Kosovo

Full list of author information is available at the end of the article
}

the areas inaccessible to other woody plants (PiękośMirkowa H 1996). In Kosovo, it is one of the native pines distributed in high altitudes too, found in the Sharri Mountains and Albanian Alps Mountains in calcareous and dolomite substrate and its populations represent an important wealth of essential oil resources available, which make this species very important in terms of economic values.

In folk medicine $P$. mugo has been documented for use in various medicinal contexts, such as for wound healing (Redzić 2007), as an antitussive (Idolo et al. 2010), rheumatic, pulmonary diseases, antiseptic, anti-inflammatory, expectorant, and fluidizing properties (Venditti et al. 2013). P. mugo has a rich and diverse composition

\section{黛 Springer}


of secondary metabolites with different biological activities including antioxidative properties (Grassmann et al. 2003, 2005), secretolytic and antimicrobial effects (Ciuman 2012).

Several studies have reported the chemical composition of the $P$. mugo essential oil originating fromdifferent regions of the world (Kartnig et al.1996; Lawrence 1996; Kartnig et al. 1997; Tsitsimpikou et al. 2001; Ochocka et al. 2002; Venditti et al. 2013; Karapandzova et al. 2011; Stevanovic et al. 2005). Variation in the content and chemical composition between populations and plant organs (needles, twigs and cones) were reported as well (Kartnig et al. 1996, 1997).

According to ISO 9909 (2003), the following range (\%) of main constituents is required in order to evaluate the quality of Pinus mugo essential oil: $\alpha$-pinene (10-30 \%), $\beta$-pinene (3-14\%), $\delta$-3-carene (5-25\%), $p$-cymene (trace-2,5\%), limonene (8-14\%), terpinolene (1-8\%), bornyl acetate (1-5 \%), (E)-caryophyllene (0.5-5 \%), myrcene (3-11\%) and $\beta$-phellandrene (8-17 \%).

Therefore, the principal aims of our study were to analyse the chemical composition of essential oils obtained from needles, twigs and cones of this plant and to assess the natural variation of essential oils between wild populations of $P$. mugo growing in Kosovo using a statistical approach with PCA and HCA.

\section{Results}

The ITS (Internal Trascribed Spacer) sequences of the $18 P$. mugo individuals exhibited identical sequence composition. No sequences of $P$. mugo were available in the public sequence database GenBank and sequences of $P$. hwangshanensis, P. taiwanensis, P. luchuensis and P. densiflora were identified as the closest relatives of our ITS sequences. Pinus mugo is a highly polymorphic taxon, it is usually divided into two subspecies: Pinus mugo subsp. mugo Turra (dwarf mountain pine) and Pinus mugo subsp. uncinata (Ramond) Domin (mountain pine) (Christensen 1987; Monteleone et al. 2006; Bogunić et al. 2011). Our analysed samples, based on their morphological characteristic (several curved trunks, long branches with base lies on the ground, while the end is erect) belong to Pinus mugo subsp. mugo. The occurrence of this subspecies in Balkans previously were recorded too (Alexandrov et al. 2011).

The results of the essential oil analysis extracted from P. mugo needles, twigs and cones essential oils collected from six locations in Kosovo are presented in Table 1. In total sixty-eight components were separated, which are listed in order of their elution from an HP-5MS column. Of these, sixty-two components were identified, which comprised $69-95 \%$ of the total composition of the oils (Table 1). Hydrodistillation of the $P$. mugo needles, twigs and cones yielded light-yellowish essential oils. The yield of essential oils differed among the plant organs and population origin. The highest essential oil content was obtained from twigs $(1.0-2.4 \% \mathrm{v} / \mathrm{w}$ per dry weight) followed by needles $(0.3-0.8 \% \mathrm{v} / \mathrm{w})$ and cones $(0.1-0.5 \%$ $\mathrm{v} / \mathrm{w})$ (Table 1).

The main compounds differed among plant organs and plant population too. In needles, the major components were: $\alpha$-pinene (17.0-24.5 \%), followed by $\delta$-3-carene (15.5-27.9\%), germacrene D (4.0-9.9\%) and $(E)$-caryophyllene (4.3-9.0\%). In twigs the major components were: $3-\delta$-carene $(24.0-51.7 \%)$ followed by limonene $+\beta$-phellandrene (12.7-24.3\%), $(E)$-caryophyllene $(4.0-10.9 \%), \beta$-pinene $(2.2-15.4 \%)$ and $\alpha$-pinene (4.5-8.8\%), whereas in cones the major components were $\delta$-3-carene $(10.5-31.5 \%)$, followed by $(E)$ caryophyllene (10.4-27.0\%), an unknown compound (0.0-24.2 \%), $\beta$-pinene (1.4-14.4\%) and germacrene D (0.1-12.4\%). Concentrations of these constituents also differed depending on the origin of the plant population (Table 1).

Monoterpenes constituted the highest percentage of all components (24.9-86.1\%), followed by sesquiterpenes (7.6-51.7\%), oxygenated sesquiterpenes (1.0-6.5\%), oxygenated monoterpenes (1.4-6.6\%), diterpenes (0.00$2.2 \%)$, other hydrocarbons (0.3-8.2\%) and an unknown compound (0.8-30.7\%).

Hierarchical cluster analysis (HCA) and principal component analyses (PCA) were used as statistical tools in order to identify possible relationships between volatile compounds obtained from plant organs (needles, twigs and cones) and geographical location of the plant populations. For statistical analyses the oil components with concentrations higher than $2 \%$ (italic in Table 1) of the total oil were selected.

The analysis of variance showed that the means for the majority of the oil compounds differed significantly $(p>0.05)$ among plant organs but not between populations (Table 1). Nevertheless, both the interaction between population location and plant organs was found to be statistically significant in respect to the chemical composition of $P$. mugo essential oil $(p>0.05)$.

The general structure of the dendrogram generated by HCA indicated the existence of three main clusters, corresponding with the chemical composition of plant organs (Fig. 1). The first cluster includes the oils obtained from twigs, the second cluster groups oils obtained from needles, whereas the third cluster groups oils obtained from cones. HCA identified the closest connection as being between needles and cones; twigs were the most distant group (Fig. 1).

PCA confirmed this clustering by HCA; the twodimensional axial system of the PCA identified three 


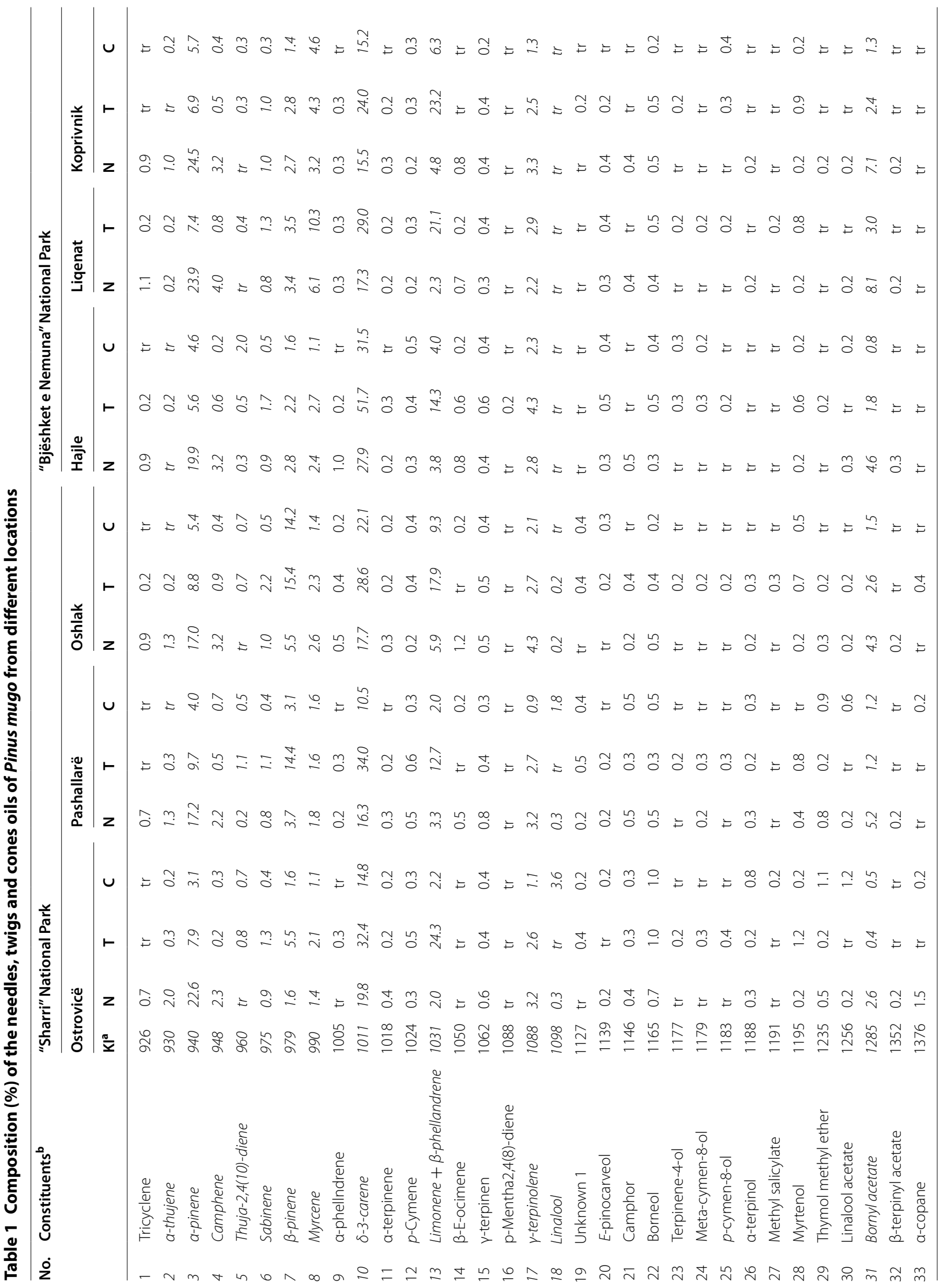




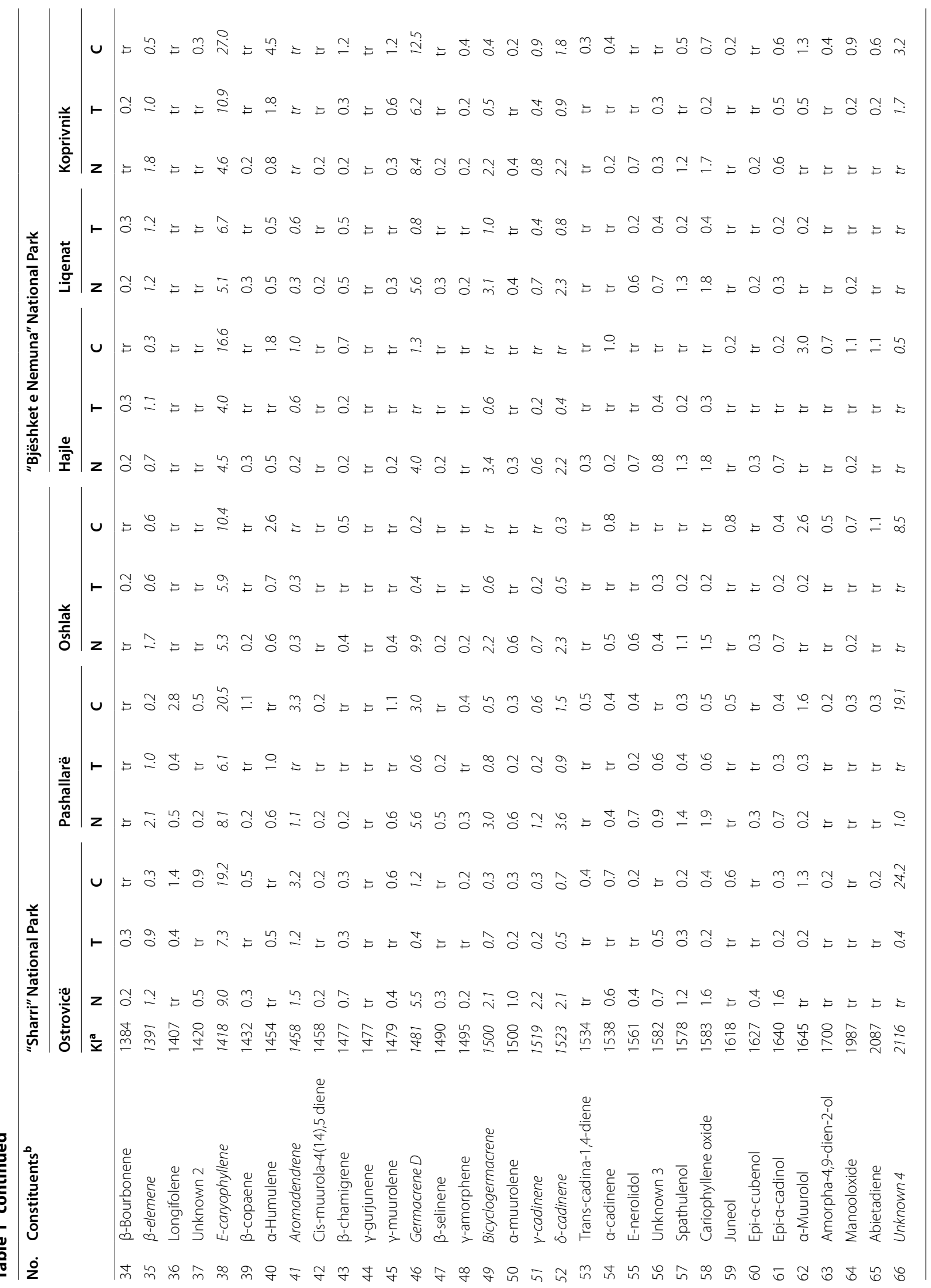




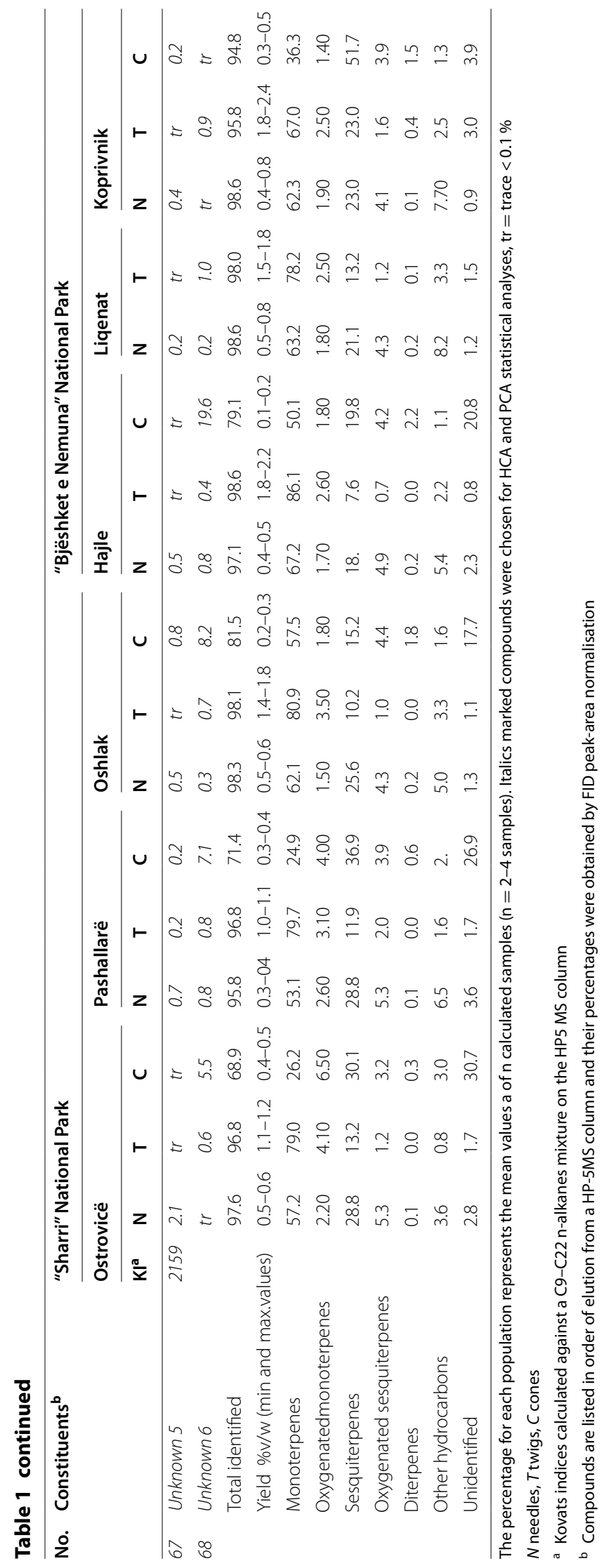




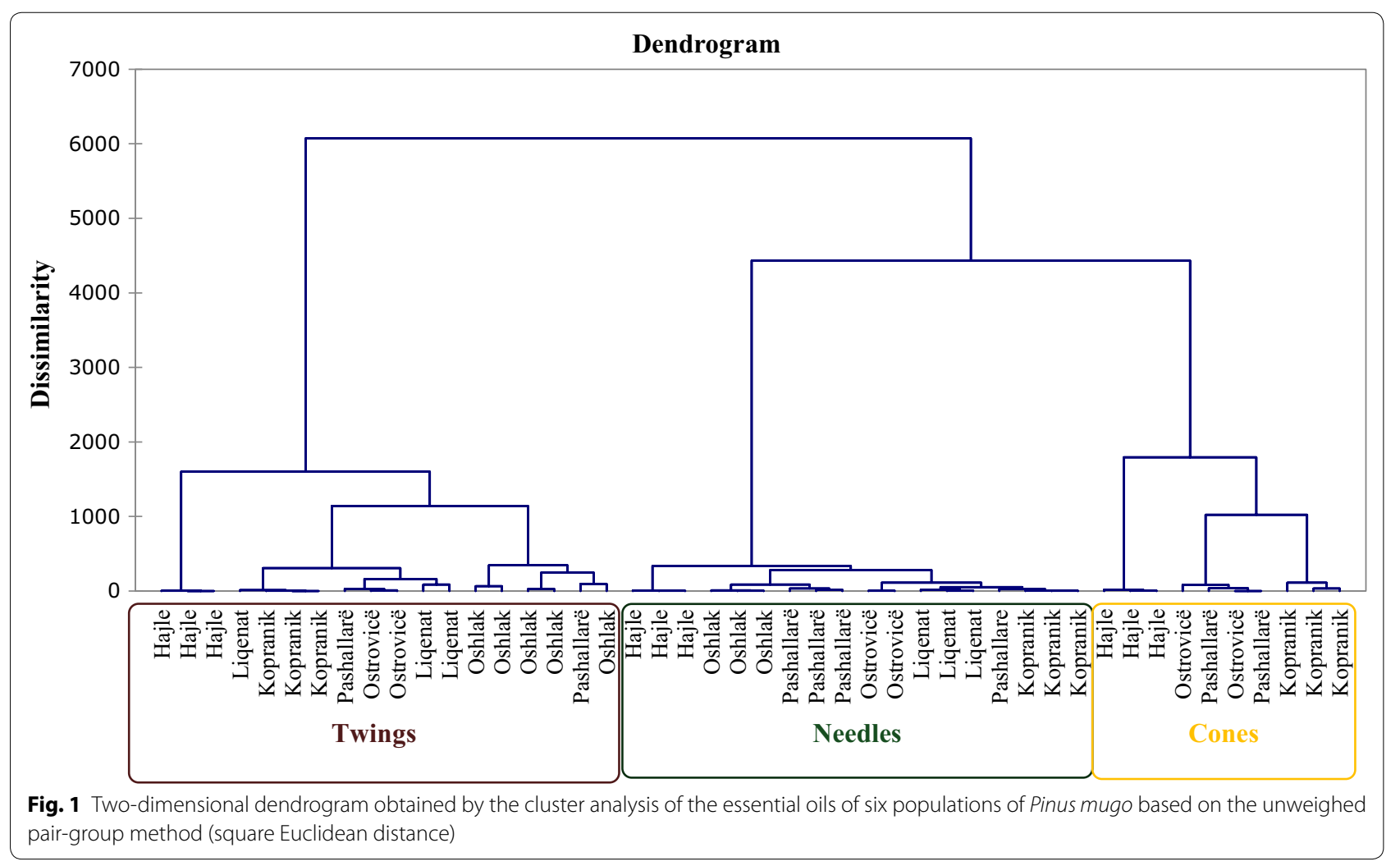

groups too. Based on the chemical composition of their essential oils, samples were grouped regarding the plant organs from which oils were obtained (Fig. 2). Camphene, $\alpha$-thujene, bicyclogermacrene, bornyl acetate, $\delta$-cadinene, $\gamma$-cadinene and germacrene $\mathrm{D}$ were the principal components that contributed to clustering of samples obtained from needles. $\delta$-3-carene, sabinene, limonene $+\beta$-phellandrene, $\beta$-pinene were the primary components that contributed to the clustering of the oils obtained from twigs, whereas $(E)$-caryophyllene, aromadendrene, linalool, $\alpha$-pinene, unknown 4 and unknown 6 were the primary components that contributed to the clustering of the oils obtained from cones. PCA results showed that the first two principal axes represented $60 \%$ of the total variance, thus, the first axis contributed with $37 \%$ of the total variation whereas the second axis with $23 \%$ (Fig. 2).

With the aim to see the variability between populations PCA was performed separately for samples obtained from needles, twigs and cones.

The two-dimensional axial system of the PCA suggests the existence of three groups of essential oils obtained from needles of $P$. mugo (Fig. 3). Thus, limonene $+\beta$-phellandrene, sabinene, germacrene $D$, $\beta$-pinene and $\beta$-elemene were the principal components that contributed to population clustering of the plants from Oshlak and Kopranik/Koprivnik. $\alpha$-Thujene, linalool, unknown no. 5, $\gamma$-cadinene, (E)-caryophyllene, aromadendrene, unknown no. $4, \delta$-cadinene were the primary components that contributed to the clustering of the population from Pashallarë and Ostrovicë. The population from Liqenat and Hajle were dominated by bornyl acetate, myrcene and $\delta$-3-carene (Fig. 3). PCA results obtained from twigs identified three groups of populations too, based on the chemical composition of their essential oils (Fig. 4). Terpinolene, $\delta$-3-carene, sabinene and aromadendrene were the principal components that contributed to population clustering of the plants from Hajle and Liqenat. Bicyclogermacrene, linalool, $\alpha$-thujene, thuja-2,4(10)-diene, $\delta$-cadinene, unknown 5 , and $\beta$-pinene were the primary components that contributed to the clustering of the population from Ostrovicë, Oshlak and Pashallarë, whereas the population from Liqenat, Kopranik/Koprivnik and Oshlak were dominated by $\beta$-elemene, myrcene, $\gamma$-cadinene, bornyl acetate, limonene $+\beta$-phellandrene, unknown no. 6 , germacrene D, unknown no. 4, $(E)$-caryophyllene (Fig. 4). The PCA results obtained from essential oil composition of cones identified three groups of populations based on the chemical composition of their essential oils (Fig. 5). Myrcene, camphene, germacrene $\mathrm{D}, \delta$-cadinene, $\gamma$-cadinene, $(E)$-caryophyllene, bicyclogermacrene and 


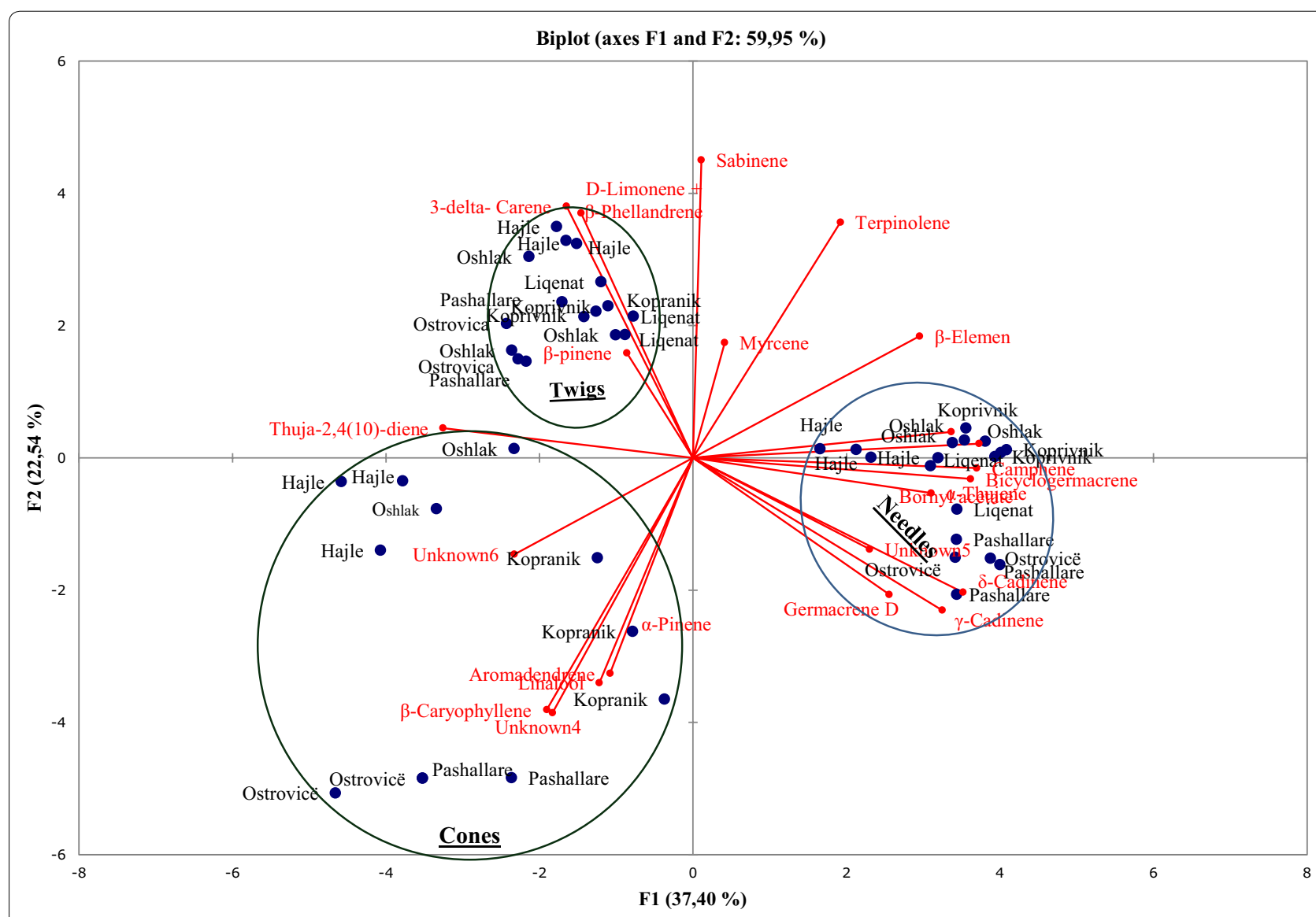

Fig. 2 Principal component analysis of the oil constituents obtained from needles, twigs and cones of six populations of P. mugo

$\alpha$-thujene were the principal components that contributed to population clustering of the plants from Kopranik/Koprivnik and a location in the site of Pashallar. Unknown no. 4, linalool and aromadendrene were the primary components that contributed to the clustering of the population from Ostrovicë, and Pashallarë. The population from Hajle and Oshlak were dominated by terpinolene, $\delta$-3-carene, sabinene, unknown 6 and thuja2,4(10)-diene (Fig. 5).

\section{Discussion}

To characterize the natural variability between $P$. mugo populations, we compared the yield and chemical composition of the essential oil collected from six locations in Kosovo. The essential oil yields of our populations differed depending on the population origins and ranged from $1.0-2.4 \% \mathrm{v} / \mathrm{w}$ weight in twigs followed by needles $(0.3-$ $0.8 \% \mathrm{v} / \mathrm{w})$ and cones $(0.1-0.5 \% \mathrm{v} / \mathrm{w})$ based on dry weight. In general, the highest yield of essential oils was found in populations originating from "Bjeshkët e Nemuna" National Park. Previous work has shown that the yield of $P$. mugo needles varied from 0.15 to $0.65 \%$ (Karapandzova et al. 2011).
In all of the Kosovar populations, the primary components in needles were $\alpha$-pinene followed by $\delta$-3-carene, germacrene and (E)-caryophyllene. $\delta$-3-carene followed by limonene $+\beta$-phellandrene, $(E)$-caryophyllene, $\beta$-pinene, $\alpha$-pinene in twigs, whereas $\delta$-3-carene, followed by $(E)$-caryophyllene, unknown no. $4, \beta$-pinene, germacrene $\mathrm{D}$ were main constituents in cones; similarly, $\alpha$-pinene, $\delta$-3-carene, $(E)$-caryophyllene were also the primary components of needles essential oils in populations from Macedonia (Karapandzova et al. 2011), $\delta$-3carene, $\alpha$-pinene, $\beta$-pinene, and $\beta$-phellandrene were main constituent of oils obtained from needles and branches of $P$. mugo originated from "Sharri" National Park (Stevanovic et al. 2005), and from Austria (Kartnig et al. 1996, 1997). The essential oil of needles originating from Edinburgh (UK), on the other hand, were reported to contain $\alpha$-pinene, $\gamma$-cadinene, caryophyllene oxide, sandaracopimara-8 (14),15-diene and $\alpha$-cadinol as main constituents (Tsitsimpikou et al. 2001). Unlike our results, the main constituents of the essential oil originating from Majella National Park (Italy) were bornyl acetate, a-terpineol (E)-caryophyllene $\alpha$-cadinol, 


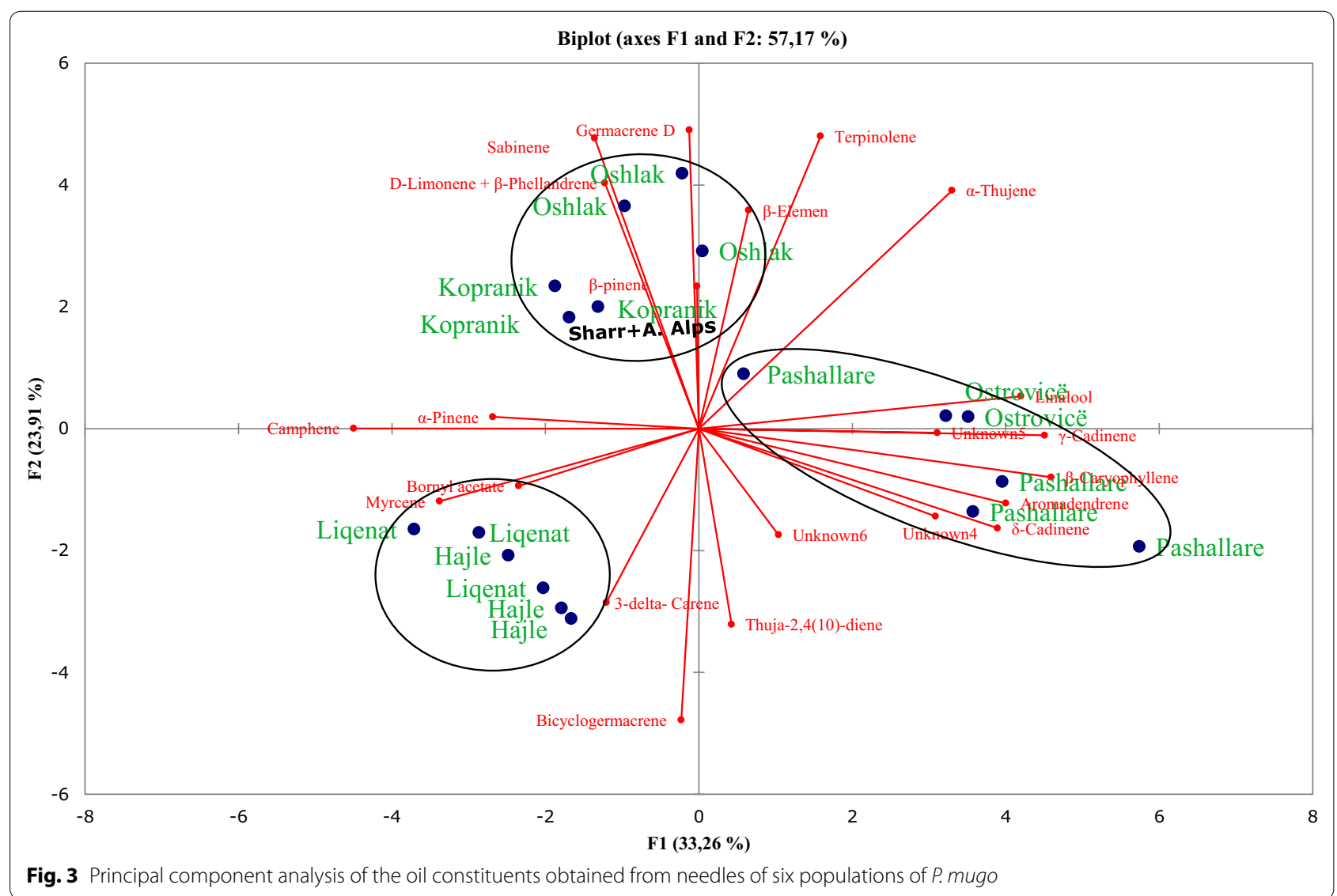

and etc. (Venditti et al. 2013). Previously, variations in $P$. mugo essential oil composition was reported for samples originating from different populations in Austria (Kartnig et al. 1996, 1997).

The quantitative composition of the essential oil obtained from needles and twigs together, with few exceptions, meets the required standards of ISO 9909 (2003), whereas essential oil obtained separately from needles and twigs do not meet ISO 9909 standards (2003) (Table 2).

The differences between plant populations were not as high as were the differences between plant organs. This is not surprising because different plant organs show a completely different gene expression profile adapted to the function of the respective organ. Small differences between the populations tested possibly indicate a high genetic relationship among the populations. The significant interaction between populations and plant organs, however, are probably an indication for an environmental influence on gene expression profiles.

PCA and HCA statistical analyses indicated the existence of three main clusters, corresponding to chemical composition of the plant organs, demonstrating that the biggest differences in essential oil chemical composition were found between plant organs. Such variation in chemical composition of the essential oil obtained from different plant organs were previously reported by (Kartnig et al. 1996, 1997). Statistical analyses also identified three main groups of populations, based on the chemical composition of the essential oils obtained separately from needles, twigs and cones. The plot established according to the first two PCA axes indicates the existence of three groups of essential oils obtained from needles $P$. mugo. The first group includes populations originating from Oshlak and Kopranik/Koprivnik ("Shari" and "Bjeshkët e Nemuna" National Park). The second group from Pashallarë and Ostrovicë ("Shari" National Park) and third from Liqenat and Hajlë ("Bjeshkët e Nemuna" National Park). Regarding the chemical composition of the essential oils obtained from twigs, PCA identified three groups of populations too; the first group included populations originating from Hajle and Liqenat (Bjeshkët e Nemuna" National Park), the second from Ostrovicë, Oshlak and Pashallarë ("Shari" National Park), and the third from Liqenat, Kopranik/Koprivnik and Oshlak ("Shari" and "Bjeshkët e Nemuna" National Park). PCA analysis of 


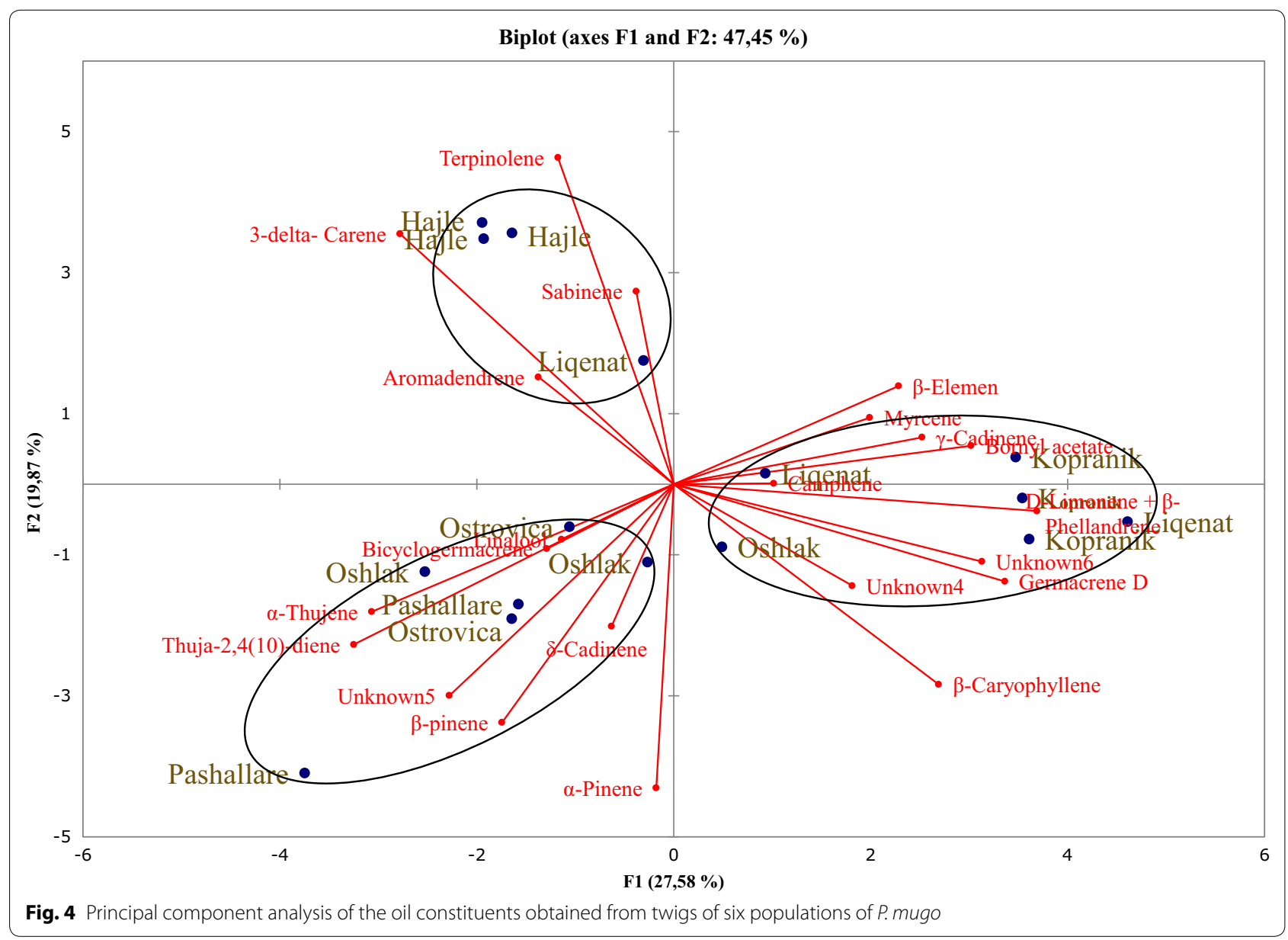

the cone essential oil composition also resulted in identification of three groups of populations as well: the first group includes populations originating from Kopranik/ Koprivnik and a location in the site of Pashallar ("Shari" and "Bjeshkët e Nemuna" National Park), the second from Ostrovicë, and Pashallarë ("Shari" National Park), and the third from Hajle and Oshlak ("Shari" and "Bjeshkët e Nemuna" National Park).

\section{Conclusions}

The yield and chemical composition of the essential oil differed depending on population origins and plant organs, thus the primary components in needles were $\alpha$-pinene followed by $\delta$-3-carene, germacrene and $(E)$-caryophyllene. $\delta$-3-carene followed by limonene $+\beta$-phellandrene, $(E)$-caryophyllene, $\beta$-pinene, $\alpha$-pinene in twigs, whereas $\delta$-3-carene, followed by $(E)$-caryophyllene, unknown no. 4 , $\beta$-pinene, germacrene D. HCA and PCA statistical analyses confirm the differences in chemical composition depending on the plant organs and the geographical origin of the plant populations. Thus, the samples used in this study were collected in two Kosovar National Parks ("Shari" and "Bjeshkët e Nemuna" National Park), which are separate from one another and located approximately $100 \mathrm{~km}$ apart. Due to geographic isolation of the mountainous areas and anemophilous pollination of the $P$. mugo, we expected to find two distinct groups based on their chemical composition of essential oils. Statistical analyses of our results did not support this hypothesis, however, as some of our samples from "Shari" and "Bjeshkët e Nemuna" National Park were grouped together. This uniformity can be explained by past distributions of this species, which was more widespread and without interruption. The current areal is a contraction of the past areal due to the climatic changes following the last ice age. Realistically, the two studied populations are a residue of a wider and older population and it is not surprising to observe similarities in their respective compositions since this separation has occurred in recent times.

The spatial distribution of the populations suggests that their clustering is not related to their geographic location, but rather seemed to be linked to local selective forces 


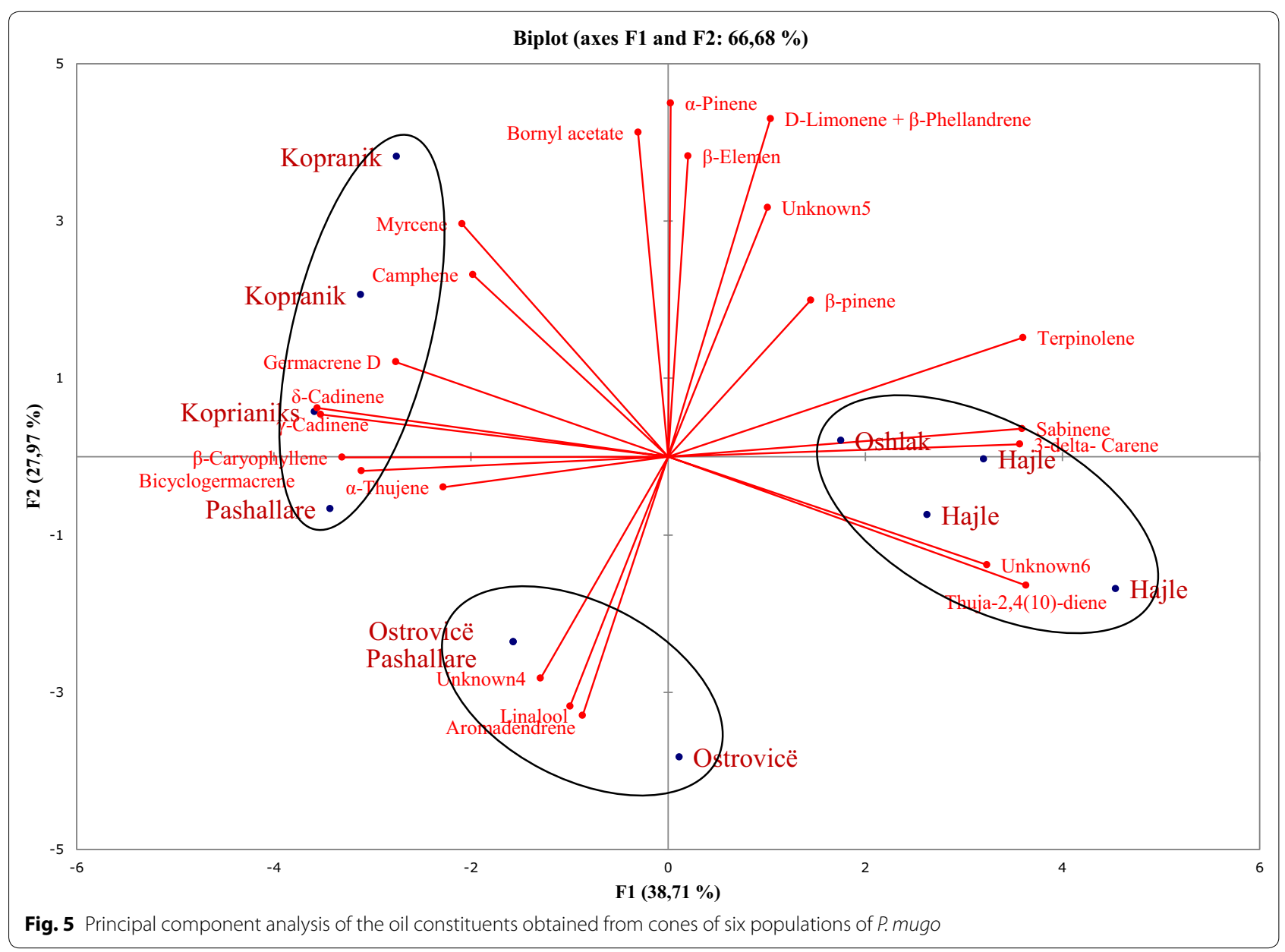

acting on chemotype diversity. Low variability related to their geographic location has an economic importance since samples originating from different locations in Kosovo can treated with same standards.

\section{Methods}

\section{Plant material}

Plant material of Pinus mugo was collected from July to September 2013 from six different wild populations in Kosovo. Three of the populations originated from "Sharri" National Park, whereas three others from "Bjeshkët e Nemuna" National Park (Fig. 6). The collection sites were recorded using a Global Positioning System (GPS) receiver (GARMIN, eTrex ${ }^{\circledR} 30$ ). Two to four replicate samples of needles, twigs and cones were analysed, each sample was gathered from 2-3 individual plants from each population. Samples were distilled and analysed separately. Voucher specimens of each population were deposited to the Herbarium of the Department of Biology, University of Prishtina.

\section{Essential oil extraction}

Plant material was air-dried in shade at room temperature and cut into small pieces $(<0.5 \mathrm{~cm})$. Separated needles, twigs (only wooden parts) and cones were subjected to essential oil distillation. For distillation, $50 \mathrm{~g}$ of dry tissue was placed into $0.5 \mathrm{~L}$ of water in a $1 \mathrm{~L}$ flask and distilled at a rate of $3 \mathrm{~mL} / \mathrm{min}$ in a Clevenger apparatus for $3 \mathrm{~h}$. The samples were stored in the dark at $-18^{\circ} \mathrm{C}$ in the freezer pending further analysis. The yield of essential oil is expressed as a percentage of the mass of the essential oil with respect to the air-dried material (\% v/w of dried material).

\section{DNA barcoding}

Nuclear ITS (internal transcribed spacer) of three individual plants of each of the six populations was sequenced to confirm species identity and to proof whether intra-specific DNA polymorphisms are present.

Genomic DNA was extracted from dried needles using a modified CTAB protocol (Doyle 1991). The internal 


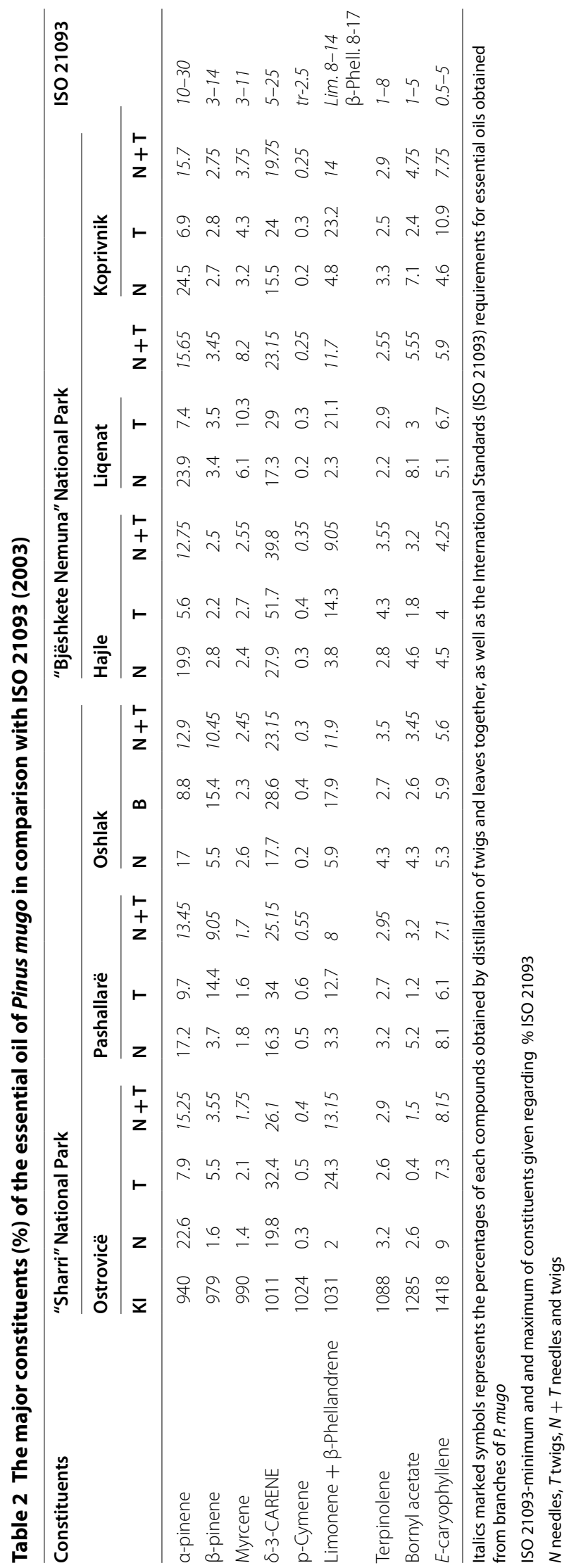




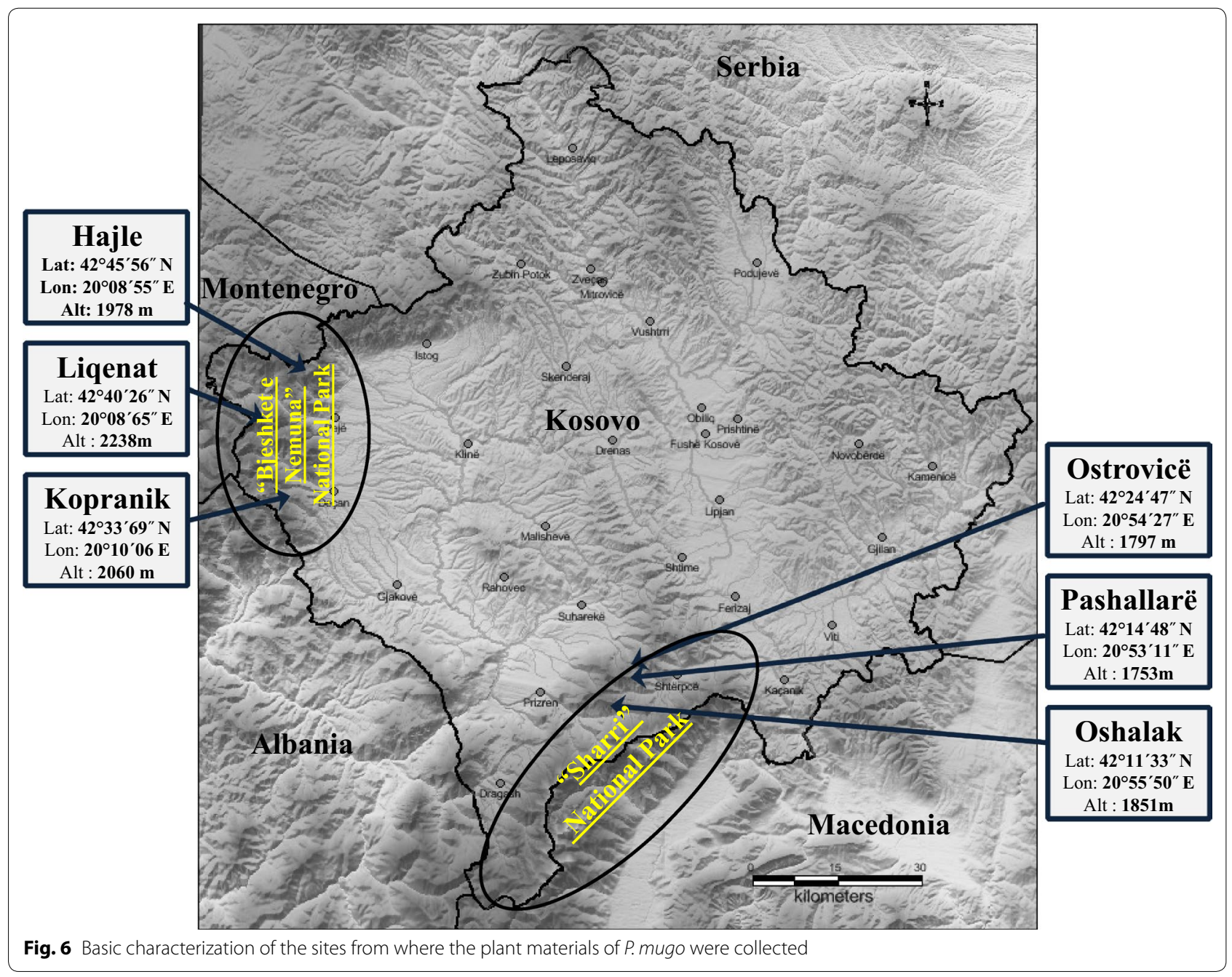

transcribed spacer (ITS) region of nuclear DNA, including ITS1, ITS2 and the $5.8 \mathrm{~S}$ gene, was amplified and sequenced with the primers PIN2451F and PIN26S25R (Nickrent et al. 1994; Liston et al. 1999). For a $15 \mu \mathrm{L}$ PCR reaction, $1 \mu \mathrm{L}$ of genomic DNA solution (1:50 dilution of the original DNA extract) was added to a master mix containing $1 \times$ PCR buffer $\mathrm{B}, 2.5 \mathrm{mM} \mathrm{MgCl}, 133 \mu \mathrm{M}$ dNTPs, 0.6 U HotFire Taq polymerase (all reagents from Solis BioDyne, Tartu, Estonia) and $0.6 \mu \mathrm{M}$ forward and reverse primer (Invitrogen, Lofer, Austria). The PCR cycle profile included an initial denaturation step at $95{ }^{\circ} \mathrm{C}$ for $15 \mathrm{~min}$, followed by 35 cycles at $95^{\circ} \mathrm{C}$ for $45 \mathrm{~s}$, at $55^{\circ} \mathrm{C}$ for $45 \mathrm{~s}$, and a final elongation step at $72{ }^{\circ} \mathrm{C}$ for $90 \mathrm{~s}$. The PCR products were purified with the enzymes ExoI and SAP (Fermentas, Burlington, Canada) and were sequenced by an external company (Ibl, Gerasdorf, Austria). The obtained sequences of the samples were edited, assembled and aligned with Geneious 5.3.4. (Biomatters Ltd.,
Auckland, New Zealand). All were deposited in GenBank (accession numbers in GenBank: KR052968- KR052986).

\section{GC and GC-MS analyses}

GC/FID analyses were performed using an Agilent 7890A GC System equipped with an FID detector (Agilent Technologies). The separation was conducted on a HP-5MS column $30 \mathrm{~m} \times 0.25 \mathrm{~mm}$ with $0.25 \mu \mathrm{m}$ film thickness. Helium was used as carrier gas with an initial flow rate of $0.6 \mathrm{~mL} / \mathrm{min}$ and subsequently at a constant pressure of $50.0 \mathrm{psi}$. The front inlet was maintained at $250{ }^{\circ} \mathrm{C}$ in a split ratio of $50: 1$. The $\mathrm{GC}$ oven temperature increased from 60 to $260{ }^{\circ} \mathrm{C}$ at a rate of $5{ }^{\circ} \mathrm{C} / \mathrm{min}$ and the FID operated at $250{ }^{\circ} \mathrm{C}$ with an air flow of $350 \mathrm{~mL} / \mathrm{min}$ and a hydrogen flow of $35 \mathrm{~mL} / \mathrm{min}$. The injection volume was $1.0 \mu \mathrm{L}$.

GC/MS analyses were performed using an Agilent 7890A GC system coupled to a 5975C MSD (Agilent 
Technologies). The ionisation energy was $70 \mathrm{eV}$ with a mass range of $40-400 \mathrm{~m} / \mathrm{z}$. The separation was conducted with the same column and temperature program as for the analytical GC.

Identification of the essential oil components was made by comparing their Kovats retention indexes with those in literature (Adams 2009). The calculation of the Kovats index was made based on a linear interpolation of the retention time of the homologous series of $n$-alkanes (C9-C22) under the same operating conditions. The components were also identified by comparing the mass spectra of each constituent with those stored in the Wiley/NIST 05.L database and with mass spectra from the literature (Adams 2009). The percentage composition of the oils was calculated in peak areas using normalization method.

\section{Statistical analysis}

Hierarchical Cluster Analysis (HCA) and Principal Component Analyses (PCA) were used to evaluate whether the identified essential oils components can be useful for reflecting the chemotaxonomy of $P$. mugo. PCA and HCA analyses were performed using the statistical analysis software, XLSTAT Version 2014.2.03 (STATCON, Witzenhausen, Germany). The oil components with concentrations higher than $2 \%$ (italic in Table 1) of the total oil were subjected to statistical analyses.

Hajdari Avni, Mustafa Behxhet, Ahmeti Gresa, Pulaj Bledar, Lukas Brigitte, Ibraliu Alban, Stefkov Gjoshe, Quave Cassandra L., Novak Johannes.

\section{Authors' contributions}

$A H, J N, G S, B M$ and $A l$ conceived and designed the study, AG, BP, LB, AH performed the laboratory work, and $A H, J N$ analyzed the data and wrote the paper; JN, BM, GS and Al provided revisions, CLQ english proofreading. All authors read and approved the final manuscript.

\section{Author details}

1 Department of Biology, Faculty of Mathematical and Natural Science, University of Prishtina, Mother Theresa St, 10000 Prishtinë, Kosovo. ${ }^{2}$ Institute of Biological and Environmental Research, Faculty of Mathematical and Natural Science, University of Prishtina, Mother Theresa St, 10000 Prishtinë, Kosovo. ${ }^{3}$ Institute of Animal Nutrition and Functional Plant Compounds, University of Veterinary Medicine, Veterinärplatz, 11210 Vienna, Austria. ${ }^{4}$ Department of Crop Production, Faculty of Agriculture and Environment, Agricultural University of Tirana, Kodër Kamëz, Tirana, Albania. ${ }^{5}$ Institute of Pharmacognosy, Faculty of Pharmacy, Ss. Cyril and Methodius University, Vodnjanska 17, 1000 Skopje, Republic of Macedonia. ${ }^{6}$ Center for the Study of Human Health, Emory University, 550 Asbury Circle, Candler Library 107E, Atlanta, GA 30322, USA. ${ }^{7}$ Department of Dermatology, Emory University School of Medicine, 1518 Clifton Road NE, CNR 5035, Atlanta, GA 30322, USA.

\section{Acknowledgements}

The authors thank the HigherKOS Project No. K-12-2012 for financial support.

\section{Competing interests}

The authors declare that they have no competing interests.

Received: 7 August 2015 Accepted: 13 December 2015 Published online: 30 December 2015

\section{References}

Adams R (2009) Identification of essential oil components by gas chromatography/mass spectrometry, 4th edn. Allured Business Media, Illinois

Alexandrov A, von Wühlish G, Vendramin G (2011) Conserving the genetic diversity of Pinus mugo Turra. Silva Balcanica 12(1):5-12

Bogunić F, Siljak-Yakovlev S, Muratović E et al (2011) Molecular cytogenetics and flow cytometry reveal conserved genome organization in Pinus mugo and P. uncinata. Ann For Sci 68:179-187. doi:10.1007/ s13595-011-0019-9

Christensen K (1987) Taxonomic revision of the Pinus mugo complex and P. $x$ rhaetica (P. mugo $\times$ sylvestris) (Pinaceae). Nord J Bot 7:383-408

Ciuman RR (2012) Phytotherapeutic and naturopathic adjuvant therapies in otorhinolaryngology. Eur. Arch. Oto-Rhino-Laryngology 269:389-397

Critchfield W, Little E (1966) Geographic distribution of pines of the world. USDA For Serv 991:1-97. doi:10.5962/bhl.title.66393

Doyle J (1991) DNA protocols for plants. In: Johnston AWBYJ (ed) Hewitt GM. Molecular Techniques in Taxonomy, Springer $V$, pp 283-285

Grassmann J, Hippeli S, Vollmann R, Elstner EF (2003) Antioxidative properties of the essential oil from Pinus mugo. J Agric Food Chem 51:7576-7582. doi:10.1021/jf030496e

Grassmann J, Hippeli S, Spitzenberger R, Elstner EF (2005) The monoterpene terpinolene from the oil of Pinus mugo $\mathrm{L}$. in concert with a-tocopherol and $\beta$-carotene effectively prevents oxidation of LDL. Phytomedicine 12:416-423. doi:10.1016/j.phymed.2003.10.005

Idolo M, Motti R, Mazzoleni S (2010) Ethnobotanical and phytomedicinal knowledge in a long-history protected area, the Abruzzo, Lazio and Molise National Park (Italian Apennines). J Ethnopharmacol 127:379-395. doi:10.1016/j.jep.2009.10.027

ISO (the International Organization for Standardization) (2003) Oil of dwarf pine (Pinus mugo Turra), vol 1. ISO no 21093. International Organization for Standardization, Geneva, pp 1-14

Karapandzova M, Stefkov GKT, Trajkovska-dokic E, Kadifkova-PanovskaT, Kaftandzieva A, Kulevanova S (2011) Chemical characterization and antimicrobial activity of the needle essential oil of Pinus mugo (Pinaceae) from Macedonian flora. Planta Med 77:PL59. doi:10.1055/s-0031-1282708

Kartnig Th, Fischer U, Bucar F (1996) Vegleichende gaschromatographische Untersuchungen an Latschenkieferolen. Sci Pharm 64:487-496

Kartnig Th, Fischer U, Bucar F (1997) Vergleichende gaschromatographische Untersuchungen an Latschenkieferölen. Mitteilun Sci Pharm 65:289-297

Lawrence BM (1996) Progress in essential oils. Perfum Flavor 21(25-28):30-32

Liston A, Robinson WA, Pinero D, Alvarez-Buylla ER (1999) Phylogenetics of Pinus (Pinaceae) based on nuclear ribosomal DNA internal transcribed spacer region sequences. Mol Phylogenet Evol 11:95-109. doi:10.1006/ mpev.1998.0550

Monteleone I, Ferrazzini D, Belletti P (2006) Effectiveness of neutral RAPD markers to detect genetic divergence between the subspecies uncinata and mugo of Pinus mugo Turra. Silva Fenn 40:391-406

Nickrent DL, Schuette KP, Starr EM (1994) a molecular phylogeny of arceuthobium (Viscaceae) based on nuclear ribosomal dna internal transcribed spacer sequences. Am J Bot 81:1149. doi:10.2307/2445477

Ochocka JR, Asztemborska M, Sybilska D, Langa W (2002) Determination of enantiomers of terpenic hydrocarbons in essential oils obtained from species of pinus and abies. Pharm Biol 40:395-399. doi:10.1076/ phbi.40.5.395.8452

Piękoś-Mirkowa H MZ (1996) Przyroda Tatrzańskiego Parku Narodowego [Nature of the Tatra National Park]. In: Mirek Z, Głowaciński Z, Klimek K P-MH (ed) Zakopane-Z. Cracow, pp. 237-274

Redzić SS (2007) The ecological aspect of ethnobotany and ethnopharmacology of population in Bosnia and Herzegovina. Coll Antropol 31:869-890

Stevanovic T, Garneau Jean F, Gagnon H, Vilotic D, Petrovic S, Ruzic N, Pichette A (2005) The essentialoil composition of Pinus mugo Turra from Serbia. Flavour Fragr J 20:96-97

Tsitsimpikou C, Petrakis PV, Ortiz A et al (2001) Volatile needle terpenoids of six Pinus species. J Essent Oil Res 13:174-178

Tutin TG, Burges NA, Chater AO, Edmondson JR, Heywood VH, Moore DM, Valentine DH, Walters DAW SM (1964) Flora europaea. Cambridge University Press, Cambridge

Venditti A, Serrilli AM, Vittori S et al (2013) Secondary metabolites from Pinus mugo Turra subsp. mugo growing in the Majella National Park (Central Apennines, Italy). Chem Biodivers 10:2091-2100. doi:10.1002/ cbdv.201300098 